\title{
INFLUENCE OF EXTRINSIC FACTORS ON CONSUMERS' CHOICE AT SEGMENTED WINE EVENTS
}

\author{
Marina Nacka ${ }^{1}$, Kristina Popova ${ }^{2}$, Riste Elenov ${ }^{3}$ \\ *Corresponding author E-mail: marina.nacka@fznh.ukim.edu.mk
}

A R T I C L E I N F O

Review Article

Received: 15 November 2019

Accepted: 01 December 2019

doi:10.5937/ekoPolj1904127N

UDC 336.14:663.285

\section{Keywords:}

wine events segmentation, wine attributes, consumer choice, label information, consumer segments.

JEL: D12
A B S T R A C T

Many wine attributes make consumer's choice difficult and confusing. By focusing on consumers from higher-segmented comparing wine events and comparing lower-segmented and higher-segmented wine events, we determinate the more influential attributes in consumers' choice, and identify what is important cue on the bottle's label. ANOVA, cluster analysis and Pearson chi-square test were used to determinate the consumers' segments and their differences, difference between attributes, influence of some of the attributes over behavioral variables. We find that recommendation influences has stronger influence over the choice of consumers at the higher-segmented event, compared to awards or information on the label. Price and design defined cluster in the lowersegmented sample while vintage, region and brand defined the high-segmented cluster.

(C) 2019 EA. All rights reserved.

\section{Introduction}

Many internal and external factors influence consumer behavior towards wine. Produces can have little influence over external or demographic factors and greater influence over internal factors, such as information about the wine and its consumption (Moulton \& Lapsley, 2001). The information derives mainly from intrinsic factors like tasting and extrinsic factors from the packaging of the bottles (Sáenz-Navajas, Campo, Sutan, Ballester, \& Valentin, 2013). This indicate that wine is a difficult and confusing product for consumers to choose due to number of cues on the label, such as brand name, region, grape variety (Lockshin, Jarvis, d'Hauteville, \& Perrouty, 2006) and the information on the front label as a first line of communication to entice the consumer (Barber, Almanza, \& Donovan, 2006).

1 Marina Nacka, Assistant Professor, Ss. Cyril and Methodius University in Skopje, Faculty of Agricultural Sciences and Food - Skopje, +38975244994, marina.nacka@,fznh.ukim.edu.mk, https://orcid.org/0000-0001-6335-5966

2 Kristina Popova, MSc Student, Ss. Cyril and Methodius University in Skopje, Faculty of Economics, Skopje, kristipopova@yahoo.com, https://orcid.org/0000-0003-3072-1266

3 Riste Elenov, Assistant Professor, Ss. Cyril and Methodius University in Skopje, Faculty of Agricultural Sciences and Food - Skopje, relenov@,fznh.ukim.edu.mk, https://orcid. org/0000-0003-1005-358X

http://ea.bg.ac.rs 
The literature suggests different influential factors in wine consumption choice such as price, packaging and labeling, brand name, region (Atkin \& Thach, 2012; Lombardo, 2012). Based on this, we determinate the key extrinsic cues used by different consumer groups when choosing wine: price, brand, recommendation, vintage, region, awards and back label information. Additionally, the consumers reliance of label information to make their purchase decision for wine determinate the selection of the following cues: producer/brand, level of alcohol and region as mandatory (MAFWE, 2010), as well as use other information that will distinguish their product (Lunardo \& Guerinet, 2007) such as vintage, label design, awards and quality sign.

Beside consumer knowledge (Gustafson, Lybbert, \& Sumner, 2016; Atkin \& Thach, 2012), choices are often made without a wealth of information, thus selecting fewer information being enticing to consumers (Barber, Almanza, \& Donovan, 2006). The choice of the product in high extend depends on consumer involvement to the product. Different categories of consumers or low involvement consumers use price and award to a greater degree than high involvement consumers (Lockshin, Jarvis, d'Hauteville, \& Perrouty, 2006). Additionally, Lockshin et al., (2006) pointed out that the award has the greatest effect for low involvement consumers. Brand and well known region of origin show important effects, which vary at different prices thus price sensitivity also varies between low and high involvement consumers.

For more experienced consumers, brand, varietal, and region collectively formed the primary driver (Reynolds, Haglund, Taylor, \& Ruetzler, 2013). With regard to the other information to distinguish the product, Hristov \& Kuhar (2014) found that recommendation as personal or credible sources of information whose opinion the consumers respect has a high influence on consumer wine purchase.

This paper attempts to present and empirically to test the main influencing factors on consumer's choice of wine and what consumers see on the bottle's label. By exploring the attributes of the wine packaging, we aim to determinate what drives consumer choice of wine in different price ranges at different wine events.

Our primary focus is set on the audience of higher-segment wine event, in order to collect insights on the wine-lovers consumers which are not done yet for this market, as to the authors' knowledge. We further widen our analysis by including more heterogeneous audience from lower-segment wine event and compare consumers' profiles and attributes affecting their choice. We consider the two wine events as industry or internally focused wine events taking into account that different events attract different audience and do not constitute a single homogenous market (Hall \& Mitchell, 2008).

As a higher-segmented event, we chose the Wine Salon in 2016 and as the lowersegmented event we chose the Winter Wine Festival in 2014. We divided the events in two categories, based on critical factors that determinate the audience to the wine event: location, timing, event facilities and activities, event program, promotion and marketing (Hall \& Mitchell, 2008). 
First, we examine attributes that influence the buyers' choice as well as identify what is important for the consumers to see on the bottle's label. A self-administered questionnaire with closed-ended and five-point Likert-type scale questions was conducted at the two different wine events.

Information were obtained for certain demographic variables (age, gender, education level, employment sector), as well as for behavioral variables (frequency of buying wine, attributes relevant for choosing which wine to buy, information stated on the bottle's label).

We test if significant differences can be found among the attributes that influence the choice of consumers when purchasing wine, by ANOVA. Additionally, we assess if gender and age group of consumers, differentiates the attributes influencing the consumers' choice. Moreover, we assess some behavioral variables, as the frequency of buying wine and the price that the consumers are willing to pay for their favorite bottle of wine, if differences in behavior reflect in differences among the attributes that influence the choice.

Following in the analysis suggested by Madeira (J., F., \& MM., 2009), cluster analysis was implemented to obtain consumer segments from the visitors of a higher-segmented wine event versus visitors of a lower-segmented wine event. To define the significant differences in the importance of certain attributes between consumers that visit highersegmented and lower-segmented events Pearson chi-square test was performed.

\section{Domestic Market Segmentation}

In the last ten years, significant investments were done in wine sector of Republic of North Macedonia (RNM). Therefore, producers tend to intensify efforts to develop a wine culture in the country by wine education of the younger generation of adults and parallel launching of more quality, branded wine (USAID AgBiz, 2012).

The majority of the consumers on this market is price sensitive and prefers low priced wine, as consequence of the low living standard of the population. Previous study on this issue, pointed out the price, the income, the gender and the level of education as main factors with greater influence on consumers ability and willingness to pay higher price for quality wine. For this category of consumers, the brand has secondary importance in their decision to purchase a quality wine (Nacka, 2015). Furthermore, the young segment of consumers on the market is highly influenced by the price of the wine as crucial factor in their choice of wine (Trajcevski, 2016).

An industry report (USAID AgBiz, 2012) defined two important consumer groups in this market; middle- aged consumers with lower purchasing power, who consume higher quantities of economy wine and more affluent young-to-middle aged adults, who prefer smaller quantities of more sophisticated wine. The second group of consumers raises the need of organizing different events to increase their wine knowledge. Organizing different wine events lacks on the market. This should be changed, because of the benefits of attracting new consumers to wine-consumption overall and to specific brands 
(Hall \& Mitchell, 2008). Furthermore, wine events would help producers to understand the consumers' profiles that are present on these wine events and would provide them leads to shift their marketing strategies. In a line to the scarce research on this issue, it raises the necessity of determining which extrinsic factors have influence on different consumers' segments on their purchasing decision. By being able to provide insights from analyzing samples of visitors on these events, this paper contributes both, to literature and to real wine sector consumer's segmentation challenges.

The results provided have implications in many directions. Firstly, we define the general profiles of consumers that visit lower-segmented and higher-segmented wine events. Secondly, the results give insights for producers in understanding which wine attributes and extrinsic cues are important to the consumers assessing if certain attributes are significantly more important than others, as well as decomposing which of the attributes is significant for consumers with different willingness to pay, different frequency of buying, or different sex and age groups. By using these results, they could focus their marketing efforts in attracting new consumers and strengthening their market position.

The paper is structured as follows. The second part presents the data used and method applied for analyzing significant differences that can be found among the attributes that influence the choice of consumers and between consumers at higher-segmented and lower- segmented wine events. In the third part, the results are presented and discussed. Finally, by defining the key extrinsic cues that influence wine choice and differences among consumers, as well as clustering the consumers, the main concussions are drawn.

\section{Materials and methods}

Following Szolonki and Hoffmann (Szolnoki \& D, 2013) who prove face-to-face survey method to deliver the most representative results over telephone and online surveys in wine consumer research, we conduct face-to-face survey on a wine event addressing 113 respondents. With the research, we try to identify which of the most often theoretically and empirically supported attributes that influence the buyers' choice are significantly more influential than the others, as well as to identify what is important for the consumers to see on the bottle's label. We also address the frequency of the wine purchase, the price they would pay for their favorite wine, as well as the place they choose to buy the wine most often from.

The survey was conducted during a wine event which had selective target of wine consumers visiting higher-segmented event. The questionnaire used in the survey was consisted of mainly close-ended questions designed to obtain information on certain demographic variables (age, gender, education level, employment sector), as well as behavioral variables (frequency of buying wine, attributes relevant for choosing which wine to buy, information stated on the bottle's label). We follow in the analysis suggested by Madeira (J., F., \& MM., 2009), however what is specific for our research is that we further apply additionally cluster analysis on a specific group of consumers in regards to their attendance on higher or lower segment wine event. 
Using the data from the survey, in the first stage, analysis was based on independence tests and ANOVA, in order to test if significant differences can be found among the attributes that influence the choice of consumers when purchasing wine. A step further was made in assessing the significance of the information that is stated on the bottle's label.

Furthermore, ANOVA was used to assess differences in the influence of some of the attributes in dependence of the sex, the age group, the frequency of buying wine, as well as the price that the consumers are willing to pay for their favorite bottle of wine.

In the second stage, cluster analysis was implemented in order to obtain consumer segments from the visitors of a higher-segmented wine event versus visitors of a lowersegmented wine event. In order to see if there are significant differences in the attributes' importance for consumers that visit high profile wine-related events, versus the consumers that visit lower profile wine-related events, we conducted Pearson's chi-square test.

\section{Events characteristics}

The higher-segmented was organized as international event with purpose to build fine wine public, to spread the wine culture through educational program, to improve the potential export and wineries' collaboration and to promote and improve the wine tourism in region. The ticket was 8.1 EUR/day. In the literature, the purpose of this kind of event is to develop awareness amongst wine consumers (Hoffman, Beverland, \& Rasmussen, 2001) and provide an educational opportunity in a non-threatening environment to develop wine appreciation and improve knowledge on wines and the wine industry (Dodd, 1995). The most present group at the event was young consumers in range of 25-34 years.

The lower-segmented wine was organized as national event with purpose to promote the wine culture in our country and the wider region. The event was not supporter by educational program instead a musical program was organized so to attract the visitors. The price of the tickets was 1.6 EUR. The most present group was consumers in range of 35 to 49 years.

\section{Sample Characteristics}

The sample from the higher segmented event consisted of 113 respondents with an average response rate of $97 \%$, defined as the number of completed questionnaires obtained divided by the number of people who were asked to complete them. This is considered to be high response rate, having into consideration that the survey was done face-to-face and similar rates are reported by Thornberry (OT., 1987), Mulry-Liggan $(\mathrm{MH}, 1983)$ in other fields of research where they applied this method.

Table 1. Sample description

\begin{tabular}{|c|c|c|c|c|c|}
\hline \multicolumn{2}{|c|}{ Age of respondents } & \multicolumn{2}{|c|}{ Gender } & \multicolumn{2}{c|}{ Frequency of buying wine } \\
\hline Under 24 & $17 \%$ & Women & $52 \%$ & Less than once a month & $6 \%$ \\
\hline $25-34$ & $33 \%$ & Man & $48 \%$ & Once a month & $12 \%$ \\
\hline $35-49$ & $46 \%$ & Total respondents & 112 & Once in two weeks & $14 \%$ \\
\hline
\end{tabular}




\begin{tabular}{|c|c|c|c|c|c|}
\hline \multicolumn{2}{|c|}{ Age of respondents } & \multicolumn{2}{|l|}{ Gender } & \multicolumn{2}{|c|}{ Frequency of buying wine } \\
\hline Above 50 & $4 \%$ & & & Once a week & $27 \%$ \\
\hline & & & & Two-three times a week & $41 \%$ \\
\hline $\begin{array}{c}\text { Total } \\
\text { respondents }\end{array}$ & 112 & & & Total respondents & 113 \\
\hline \multicolumn{3}{|c|}{ How much would you pay for your favorite wine? } & & $\begin{array}{c}\text { In which industry do you } \\
\text { work? }\end{array}$ & \\
\hline$>1000 \mathrm{MKD}$ & $26,5 \%$ & & & Unemployed & $12 \%$ \\
\hline $1000 \mathrm{MKD}$ & $26,5 \%$ & & & Other & $23 \%$ \\
\hline $600 \mathrm{MKD}$ & $33,6 \%$ & \multicolumn{2}{|c|}{$\begin{array}{c}\text { Where do you buy your } \\
\text { wine? }\end{array}$} & Trade and Logistics & $9 \%$ \\
\hline $300 \mathrm{MKD}$ & $13,3 \%$ & Own production & $5 \%$ & Science and Education & $12 \%$ \\
\hline $150 \mathrm{MKD}$ & $0,0 \%$ & $\begin{array}{c}\text { From relatives and } \\
\text { Friends }\end{array}$ & $4 \%$ & $\begin{array}{c}\text { Business, Consultancy, } \\
\text { Marketing Services }\end{array}$ & $10 \%$ \\
\hline \multirow[t]{4}{*}{$\begin{array}{c}\text { Total } \\
\text { respondents }\end{array}$} & 113 & Specialized Stores & $15 \%$ & Manufacturing Industry & $11 \%$ \\
\hline & & $\begin{array}{l}\text { Directly from the } \\
\text { manufacturers }\end{array}$ & $24 \%$ & Tourism & $12 \%$ \\
\hline & & Supermarket & $52 \%$ & Financial Services & $13 \%$ \\
\hline & & Total respondents & 111 & Total respondents & 112 \\
\hline
\end{tabular}

Source: Authors own calculations

Most of the respondents were aged between 18 and 58 years old. The sample was almost identically split between men and women representatives. Great part of the respondents answered that they would pay 600 MKD (10 EUR) for their favorite wine $(33.6 \%)$, and a little over half of them answered that they would pay 1.000 or more MKD (16 EUR) (53\%). From this structure we could see that most of the visitors of the higher-segmented event would pay above the middle price for their favorite bottle of wine. Having in mind that none of the respondents seems to think that their favorite wine could be bought for a very low price of 150 MKD (2.4 EUR), we can logically assume that the consumers put into positive relation the price and the quality of wine.

From the frequency of buying wine, we could conclude that most of the respondents buy wine on regular basis and really often. Sixty-eight percent of the respondents buy wine at least once a week, two times a week and three times a week. When it comes to the place of purchase, respondents prefer the supermarkets $(52 \%)$, whereas some of them purchase directly from the producers $(24 \%)$. When it comes to analyzing the question in which industry does the respondent work, we can see that the sample is pretty diverse, consisting of almost identical participation of all of the sectors listed in the questionnaire.

Wine consumers that visit higher-segmented events consider the recommendations to be the attribute that has the highest importance on average, over their wine choice (ranked 4.1). The brand (ranked 3.9), vintage (ranked 3.8) comes second and third. The geographical regions, as well as the price are equally affecting the consumers' choice on average (ranked 3.7). The least important are the awards (ranked 3.4) and before them are the information that can be found on the label of the bottle (ranked 3.5). 
From the information consisted on the bottle's label, the wine consumers that visit higher-segmented events, consider the variety to be the most important information on average (ranked 4.3). The geographical region, brand winery or product brand, as well as the vintage are found to be equally important on average (ranked 3.8). The design and color of the label is considered to be more important for these consumers than the percentage of alcohol consisted in the wine (ranked 3.4, versus 3.2), however less important from the awards granted and quality logos (ranked 3.6).

\section{Results and discussion}

This part is divided into three segments: insights on the consumers from the highersegmented wine event; clusters of the audience of higher and lower segmented wine events; differences of importance of certain attributes to consumers in dependence of the type of event visited.

\section{Insights on attributes affecting}

The consumers taking the survey were asked to choose how strong the influence of the attributes over their choice is. The results from the analysis on the sample from the higher-segment wine event pointed out indifference of the consumers when considering year of harvesting as an attribute, the geographic origin, and the price.

A statistically significant difference exists between Recommendations and Awards (with mean difference of $0.7256, \mathrm{p}=0.000$ ) and Recommendations and the Information on the label of the bottle (with mean difference of $0.6199, p=0.002$ ), both indicating the recommendations to have stronger influence over the choice of consumers, over the awards and information on the label of the bottle.

Another statistically significant importance exists between the brand and the award (with mean difference of $0.5700, \mathrm{p}=0.007$ ), indicating the brand of the wine to have stronger influence than the awards for the consumers on higher-segmented events. This is in line with Barber (2008) who stressed that consumers will seek varying external information sources when making need-satisfying purchase decisions, relying on others' opinions and experiences.

To get better insight, we assessed if consumers with different gender or age groups appreciate differently attributes that influence their choice of wine. Moreover, we assessed if the consumers with different behavioral characteristics: frequency of buying wine and the amount of money they would pay for their favorite wine, appreciate differently the attributes influencing their choice.

There is only one statistically significant relationship between gender and attributes affecting consumers' choice - geographical origin (with mean difference of 0.5150 , $\mathrm{p}=0.026$ ). Men consumers value more the geographical origin than women. For both man and women, the label did not have significant influence on the choice of wine. This is opposite of the findings that emphases the design of the label as a top priority for both men and women (Lombardo, 2012). 


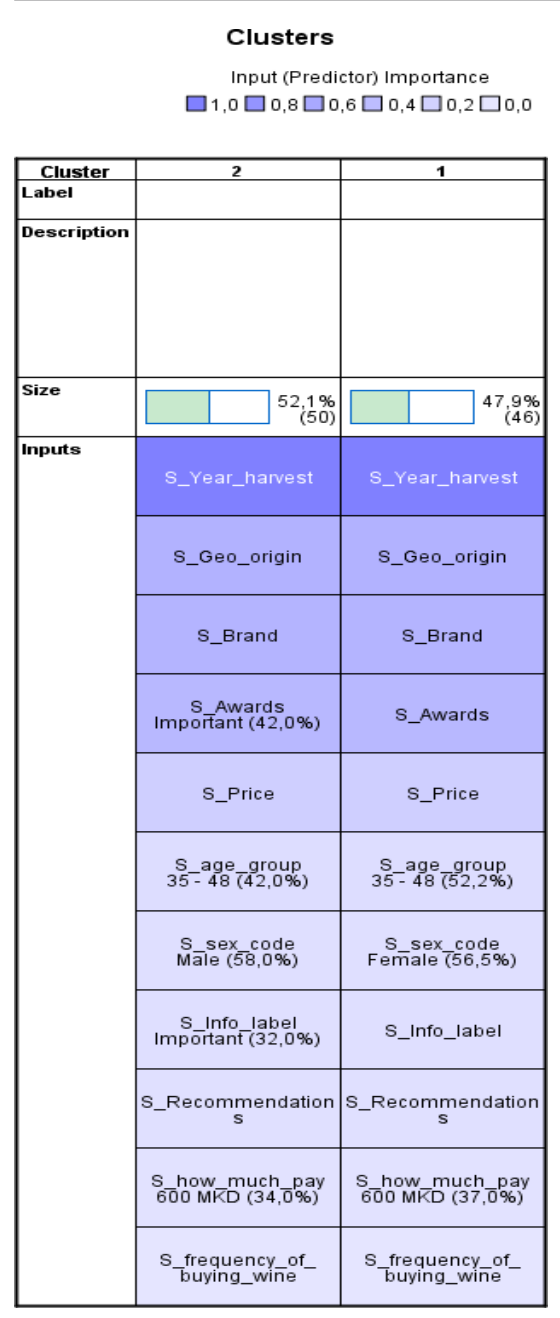

There is statistically significant difference between the consumers aged under 24 yearsold, and the consumers aged 25 to 34 yearsold, for the influence of the recommendations as an attribute of choice. The second, gave on average higher grade on the recommendation as an influencing factor (mean difference of 1.0602, $\mathrm{p}=0.004$ ). Consumers buying wine as frequent as two to three times a week, tend to show higher importance of the price as factor of choice, over the consumers buying wine once a week (with mean difference of 0.7212, $\mathrm{p}=0.047$ ).

A statistically significant difference can be seen between the consumers that would pay more than 1.000 MKD (16 EUR) and the consumers that would pay around 300 MKD (5 EUR), the first appreciating the geographical origin of the wine as an attribute that influences their choice (with mean difference of $1.095, \mathrm{p}=0.032$ for the higher-segment and $0.6175, \mathrm{p}=0.013$ for overall sample of both higher and lower segment).

\section{Market segmentation}

In order to have better insights on the consumers' profile, we conducted cluster analysis on the sample of visitors on higher-segment wine events, as well as cluster analysis on the sample of lower-segment wine events. Two-step Cluster is an algorithm designed to analyze large datasets grouping the observations of the sample in clusters by using the approach criterion. The procedure uses agglomerative hierarchical clustering method. Compared to classical methods of cluster analysis, the Two-step cluster analysis enables both continuous and categorical attributes. Moreover, the method can automatically determine the optimal number of clusters and these are the reasons for choosing it.

The Two-step cluster analysis detected two separate clusters in the sample of the visitors on higher-segment wine events. The attributes that define the clusters are the vintage, geographical region and the brand of wine.

The first cluster from the higher-segment wine event sample is dominated by women consumers aged 35 to 49 years-old that tend to buy wine two or three times a week and would pay for their favorite wine 600 MKD (10 EUR). They consider the price, the awards, the brand of the wine, as well as the geographical region, label information and vintage to be out of moderate importance for their choice of wine (ranked 3 out of 5). 
However, they put the recommendations very high on their importance scale (ranked 5 out of 5$)$.

The second cluster from this sample is dominated by men consumers aged 35 to 49 years-old who tend to buy wine two-three times a week and are willing to pay 600 MKD (10 EUR) for their favorite wine. In this cluster consumers rank the vintage, the geographical region, the brand and price as very important (ranked 5 out of 5). Furthermore, they appreciate more the awards granted and the label information on the bottle of wine compared to the first cluster. The recommendations are very important for this cluster's consumers as well (ranked 5 out of 5).

What is common for the both clusters that resulted from the higher-segment wine event is that the both are dominated by pretty frequent buyers of wine aged 25 to 34, who appreciate the recommendations very much (ranked 5 out of 5) and are willing to pay around $600 \mathrm{MKD}$ (10EUR) for their favorite bottle of wine. This description is relevant, regardless of the sex of the consumers. What is different among them is the sensitivity of the attributes such as geographical region, vintage, brand and price of wine which are more appreciated by the men consumers.

The cluster analysis done on the sample of wine consumers that visited lower-segment wine event, resulted in two clusters as well. The greatest influence in defining the clusters had how much would the consumers pay for their favorite wine and how important was the design for them.

The first cluster from this sample was dominated by women consumers aged bellow 24 that tend to buy wine two or three times a week. Most of the cluster members would pay for their favorite wine $600 \mathrm{MKD}$ (10 EUR). The members of this cluster consider the geographical region, the brand and the price of the wine to be very important (ranked 5 out of 5). On the other hand, most of them consider the variety to be moderately important (ranked 3 out of 5). This cluster can be identified as college/university drinkers since it is pre dominated by young consumers.

The second cluster was dominated by the male consumers aged 25 to 34 years old that buy wine once a week and would pay for their favorite wine 1.000 MKD (16 EUR). They think that the geographical region, the brand, the design and the price to be moderately important (ranked 3 out of 5). However, they consider the variety to be very important (ranked 5 out of 5 ).

The lower-segment wine events attract pretty heterogonous consumers in terms of the price that they are willing to pay, the age group they belong to and what they seem to find more important from the wine attributes. The variety seems to be factor of difference for the two clusters, since the first find it less important than the second compared to the other listed attributes. However, the second would pay more for their favorite wine and in regards to their age, we could safely say that they are representatives of the consumers' category of young adults (Townshend \& Duka, 2005). 
This is line with (Hall \& Mitchell, 2008) who stressed that different wine events target different audience with different behavior profiles. Therefore, organization of different wine events with educational character is important in increasing consumer knowledge and should incorporate and understand the behavior of the events visitors in the marketing and promotional strategies (Hall \& Mitchell, 2008).

\section{Comparing consumers from both - higher and lower segment events}

The results in general, present significant differences among consumers segments at the different wine events. The differences are in line with assumed consumers' profiles with regard to the characteristics of each wine event.

We have also analyzed if respondents' demographic characteristics influence over their behavior. By conducting ANOVA, we have discovered that for the consumers in the higher-segmented events, the gender has influence over the frequency of buying ( $\mathrm{F}$ $(1,110)=5.607, p=0.020$ with mean difference of 0.559$)$ indicating that male consumers buy wine more frequently than women. There was no indication that gender has influence over the price a consumer would pay for their favorite wine $(F(1,110)=1.221, p=0.271)$. It is interesting, that the gender influence is also confirmed for the consumers in the lower-segment wine events $(\mathrm{F}(1,398)=6.715, \mathrm{p}=0.010)$ indicating the men consumers purchase wine more frequently. On the other side, effect was discovered between the gender and the price a consumer would pay for their favorite wine.

We analyzed the relationship between the consumers visiting higher segment wine events versus the consumers visiting lower segment wine events in regards to the importance of couple of attributes including the brand of the wine, the variety, the price, the geographical region and the label design and color, by applying Pearson's chi-square test. The test proved to be in favor of the alternative hypothesis for each of the attributes considered, proving that there is a relationship between the attributes and the consumers visiting different types of wine events $(\alpha=0.05)$.

The strength of the relationship was assessed with Cramer's V test which is recommended as the most useful when considering variables that have more than two categories.

Table 2 Pearson's Chi-square Results

\begin{tabular}{|l|c|c|c|c|c|}
\hline & Brand & $\begin{array}{c}\text { Geographical } \\
\text { Region }\end{array}$ & Price & $\begin{array}{c}\text { Label Design } \\
\text { and Color }\end{array}$ & Variety \\
\hline Chi-square & 15.046 & 4 & 7 & 21 & 19 \\
\hline Deg. Freedom & 4 & 4 & 4 & 6 & 4 \\
\hline p. sig. $(\alpha=0.05)$ & 0.005 & 0.000 & 0.000 & 0.001 & 0.001 \\
\hline Cramer's V & 0.257 & 0.094 & 0.182 & 0.320 & 0.470 \\
\hline Sample size & 508 & 512 & 509 & 509 & 507 \\
\hline
\end{tabular}

By post-hoc comparison of the relative frequencies, we manage to determine significant difference in the importance of the brand, as well as the variety. The consumers from 
the higher-segment event seem to value these attributes much more than the consumers from the lower-segment wine events.

Figure 1 Importance of the brand

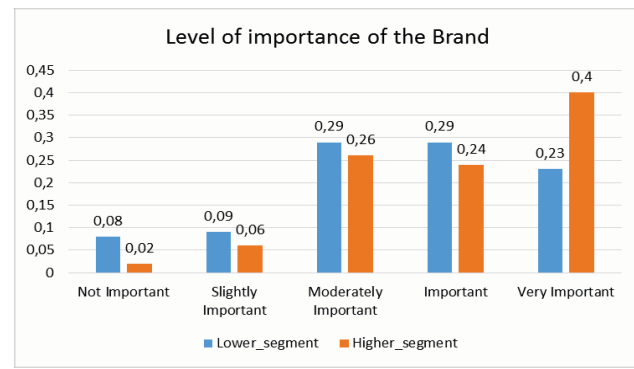

Figure 2 Importance of variety

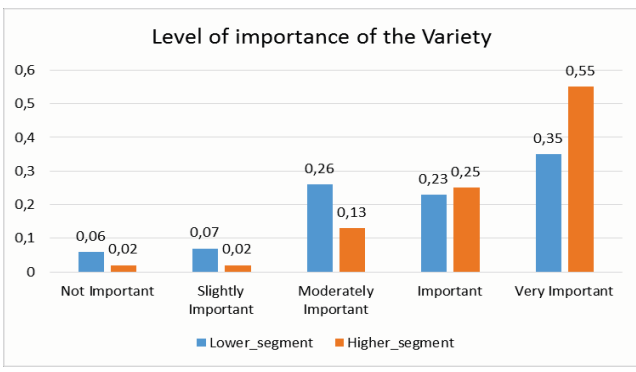

Source: Authors own calculations and presentation of relative frequencies

\section{Conclusions}

Empirically testing the theoretical assumptions of the attributes having effect over the wine consumer's provides useful insight both to the real wine sector consumer's segmentation challenges, and the literature overall. By analyzing the different type of consumers that visit wine events would help producers to understand the consumers' profiles and would provide them leads to shift their marketing strategies.

The results provided in this research of the attributes affecting consumer's choice, as well as providing market segmentation, have implications in two main directions. Firstly, we define the general profiles of consumers that visit lower-segmented and higher-segmented wine events.

Secondly, the results give insights for producers in understanding which wine attributes and extrinsic cues are important to the consumers assessing if certain attributes are significantly more important than others, as well as decomposing which of the attributes is significant for consumers with different willingness to pay, different frequency of buying, or different sex and age groups. By using these results, they could focus their marketing efforts in attracting new consumers and strengthening their market position.

What is characteristic for the higher-segment wine event consumers is that it is dominated by pretty frequent buyers of wine aged 25 to 34 , who appreciate the recommendations very much and are willing to pay around $600 \mathrm{MKD}$ (10EUR) for their favorite bottle of wine. This conclusion is relevant, regardless of the gender of the consumers. However, there is different attributes sensitivity of these consumers in regards to their sex when it comes to valuing the importance of the geographical region, vintage, brand and price. Male consumers find more important these attributes than female wine consumers from the higher-segment events.

The lower-segment wine events attract pretty heterogonous consumers in terms of the price that they are willing to pay, the age group they belong to and what they seem to 
find more important from the wine attributes. From the analysis done, it can be clearly seen that there is typical college drinkers' group, dominated by female consumers that buy wine pretty often and are willing to pay around $600 \mathrm{MKD}$ (10 EUR) for the favorite bottle of wine, and young adults' group on the other side. The second considers the variety to be very important attribute, tends to buy wine once a week and would pay for their favorite wine 1.000 MKD (16 EUR).

When analyzing in details the higher-segment event consumers, the results show that recommendation is very important for the age group of young adults, compared to the college drinkers aged bellow 24 years old. The consumers that would pay more than 1.000 MKD (16 EUR) find the geographical region of the wine as a very important attribute, compared to the consumers that would pay only $300 \mathrm{MKD}$ (5 EUR). Women consumers from this segment seem to value the brand higher than men consumers. When analyzing the data in regards on the information on the bottle's label, than we can note that men consumers on average value more the geographical region than women. Consumers that buy wine once a week give more value to the price of the wine from the consumers that buy wine two or three times a week.

Consumers who are ready to pay lower price for the wine show higher attractiveness to the label design and for both, man and women, do not have significant influence on their choice of wine. However, consumers at lower-segmented event are mostly affected by the price than other wine attributes. Compared to higher-segmented event, this event attracts segment of consumers with different behavior profiles that values wine attributes much more than lower-segmented event visitors. Therefore, the organization of higher-segmented wine events with educational character has proved to be important for targeting higher-segmented consumers and increasing consumers' knowledge. Wineries should offer quality wines that will be recognized and recommended to the consumers as important extrinsic factor, and should incorporate the behavior of the events visitors in their marketing and promotional strategies.

\section{Conflict of interests}

The authors declare no conflict of interest.

\section{References}

1. Atkin, T., \& Thach, L. (2012). Millennial wine consumers: risk perception and information search. Wine Economics and Policy, 1(1), 54-62 https://doi. org/10.1016/j.wep.2012.08.002

2. Barber, N. A. (2008). How self-confidence and knowledge effects the sources of information selected during purchase situations (Doctoral dissertation, Texas Tech University).

3. Barber, N. (2009). Wine consumers information search: Gender differences and implications for the hospitality industry. Tourism and Hospitality Research, 9(3), 250-269. https://doi.org/10.1057/thr.2009.14 
4. Barber, N., Almanza, B. A., \& Donovan, J. R. (2006). Motivational factors of gender, income and age on selecting a bottle of wine. International Journal of wine marketing, 18(3), 218-232. https://doi.org/10.1108/09547540610704774

5. Dodd, T. H. (1995). Opportunities and pitfalls of tourism in a developing wine industry. International Journal of wine marketing, 7(1), 5-16. https://doi. org/10.1108/eb008636

6. Gustafson, C. R., Lybbert, T. J., \& Sumner, D. A. (2016). Consumer knowledge affects valuation of product attributes: Experimental results for wine. Journal of Behavioral and Experimental Economics, 65, 85-94. https://doi.org/10.1016/j. socec.2016.08.004

7. Michael, H. C., \& Mitchell, R. (2008). Wine Marketing a practical guide.

8. Hoffman, D., Beverland, M., \& Rasmussen, M. (2001). The evolution of wine events in Australia and New Zealand: A proposed model. International Journal of Wine Marketing, 13(1), 54-71. https://doi.org/10.1108/eb043370

9. Hristov, H., \& Kuhar, A. (2014). Young urban adults preference for wine information sources: An exploratory study for Republic of Macedonia (No. 727-2016-50308). https://doi.org/10.22004/ag.econ.184855

10. Madeira, J., Duarte, F., \& Barreira, M. M. (2009). Wine purchase and consumption behaviour of young adults in Portugal: Is age a differentiation factor?. Age, 15(24)

11. Lockshin, L., Jarvis, W., d'Hauteville, F., \& Perrouty, J. P. (2006). Using simulations from discrete choice experiments to measure consumer sensitivity to brand, region, price, and awards in wine choice. Food quality and preference, 17(3-4), 166-178. https://doi.org/10.1016/j.foodqual.2005.03.009

12. Lombardo, C. (2012). Gender Preferences in Wine Marketing. https:// digitalcommons.calpoly.edu/agbsp/101

13. Lunardo, R., \& Guerinet, R. (2007). The influence of label on wine consumption: its effects on young consumers' perception of authenticity and purchasing behavior. International marketing and trade of quality food products, 1, p279-291. https://doi.org/10.3920/978-90-8686-661-8

14. MAFWE. (2010). Law on Wine. Skopje: Ministry of Agriculture, Forestry and Water economy. State Gazzette

15. Mulry-Liggan, M. H. (1983). A comparison of a random digit dialing survey and the current population survey. In Proceedings of the American Statistical Association, Section on Survey Research Methods. Washington, DC: American Statistical Association (pp. 214-219).

16. Moulton, K., \& Lapsley, J. (2001). Successful Wine Marketing. Aspen Publishers.

17. Nacka, M. (2015). Use of geographical indications in marketing modeling of wine sector in Republic of Macedonia. PhD. Skopje: Faculty of Agricultural Sciences and food-Skopje. 
18. Nacka, M., Georgiev, N., \& Simonvska, A. (2016). Young consumer preferences for Macedonian wine, Journal "Agriculture and Forestry, Volume 62/Issue 2, University of Montenegro. https://doi.org/10.17707/AgricultForest.62.2.09

19. OT., T. J. (1987). An experimental comparison of telephone and personal health interview surveys. Vital and health statistics. Series 2, Data Evaluation and methods research (106), 1-4.

20. Reynolds, D., Haglund, I., Taylor, J., \& Ruetzler, T. (2013). Wine Purchase Intentions: A Push-Pull Study of External Drivers, Internal Drivers, and Personal Involvement. American Association of Wine Economists 2013 Annual Conference.

21. Sáenz-Navajas, M. P., Campo, E., Sutan, A., Ballester, J., \& Valentin, D. (2013). Perception of wine quality according to extrinsic cues: The case of Burgundy wine consumers. Food Quality and Preference, 27(1), 44-53. https://doi.org/10.1016/j. foodqual.2012.06.006

22. Szolnoki, G., \& Hoffmann, D. (2013). Online, face-to-face and telephone surveys - Comparing different sampling methods in wine consumer research. Wine Economics and Policy, 2(2), 57-66. https://doi.org/10.1016/j.wep.2013.10.001

23. Trajcevski, H. (2016). Consumer behavior in selection of wine-impact of factors. VI Student Review of scientific papers. Skopje: Faculty of agricultural sciences and food-Skopje.

24. USAID AgBiz. (2012, February). Macedonia’s Wine Sector Export Marketing Plan for EU Markets. USAID.

Appendix 1: Sample descriptives, ANOVA results and multiple comparisons results

\begin{tabular}{|c|c|c|c|c|c|c|c|c|}
\hline \multicolumn{9}{|c|}{ Descriptives } \\
\hline & \multirow{2}{*}{$\mathrm{N}$} & \multirow{2}{*}{ Mean } & \multirow{2}{*}{$\begin{array}{c}\text { Std. } \\
\text { Deviation }\end{array}$} & \multirow{2}{*}{$\begin{array}{l}\text { Std. } \\
\text { Error }\end{array}$} & \multicolumn{2}{|c|}{$\begin{array}{l}95 \% \text { Confidence } \\
\text { Interval for Mean }\end{array}$} & \multirow{2}{*}{ Minimum } & \multirow{2}{*}{ Maximum } \\
\hline & & & & & $\begin{array}{l}\text { Lower } \\
\text { Bound }\end{array}$ & $\begin{array}{l}\text { Upper } \\
\text { Bound }\end{array}$ & & \\
\hline S_Brand & 111 & 3,937 & 1,0811 & , 1026 & 3,734 & 4,140 & 1,0 & 5,0 \\
\hline S_Year_harvest & 109 & 3,771 & 1,2220 &, 1170 & 3,539 & 4,003 & 1,0 & 5,0 \\
\hline S_Geo_origin & 108 & 3,676 & 1,2061 &, 1161 & 3,446 & 3,906 & 1,0 & 5,0 \\
\hline S_Info_label & 110 & 3,473 & 1,2319 &, 1175 & 3,240 & 3,706 & 1,0 & 5,0 \\
\hline S_Awards & 109 & 3,367 & 1,2595 & ,1206 & 3,128 & 3,606 & 1,0 & 5,0 \\
\hline S_Recommendations & 108 & 4,093 & 1,1236 &, 1081 & 3,878 & 4,307 & 1,0 & 5,0 \\
\hline S_Price & 108 & 3,657 & 1,1204 & , 1078 & 3,444 & 3,871 & 1,0 & 5,0 \\
\hline Total & 763 & 3,710 & 1,1977 &, 0434 & 3,625 & 3,795 & 1,0 & 5,0 \\
\hline
\end{tabular}




\begin{tabular}{|l|r|r|r|r|r|}
\hline \multicolumn{7}{|c|}{ ANOVA } \\
\hline & $\begin{array}{c}\text { Sum of } \\
\text { Squares }\end{array}$ & \multicolumn{1}{c|}{ Df } & \multicolumn{1}{c|}{ Mean Square } & F & Sig. \\
\hline Between Groups & 41,369 & 6 & 6,895 & 4,957 &, 000 \\
\hline Within Groups & 1051,619 & 756 & 1,391 & & \\
\hline Total & 1092,988 & 762 & & & \\
\hline
\end{tabular}

The p-value is lower than the 0.05 significance level indicating rejection of the null hypothesis.

\begin{tabular}{|c|c|c|c|c|c|c|}
\hline \multicolumn{7}{|c|}{ Multiple Comparisons } \\
\hline \multirow{2}{*}{$\begin{array}{c}\text { Tukey HSD } \\
\text { (I) V1 }\end{array}$} & \multirow[b]{2}{*}{ (J) V1 } & \multirow{2}{*}{$\begin{array}{c}\text { Mean } \\
\text { Difference } \\
(\mathrm{I}-\mathrm{J}) \\
\end{array}$} & \multirow{2}{*}{$\begin{array}{l}\text { Std. } \\
\text { Error }\end{array}$} & \multirow[b]{2}{*}{ Sig. } & \multicolumn{2}{|c|}{ 95\% Confidence Interval } \\
\hline & & & & & $\begin{array}{l}\text { Lower } \\
\text { Bound }\end{array}$ & Upper Bound \\
\hline \multirow{6}{*}{ S_Brand } & S_year_harvest &, 1663 &, 1590 & ,943 & $(, 304)$ & ,636 \\
\hline & S_geo_origin & ,2610 &, 1594 & ,658 & $(, 210)$ & ,732 \\
\hline & S_info_label & ,4642 &, 1587 &, 055 & $(, 005)$ & ,933 \\
\hline & S_awards &, $5700^{*}$ &, 1590 & 007 &, 100 & 1,040 \\
\hline & S_recommendation & $(, 1557)$ &, 1594 & ,959 & $(, 627)$ & ,316 \\
\hline & S_price & ,2795 &, 1594 &, 580 & $(, 192)$ & ,751 \\
\hline \multirow{6}{*}{ S_year_harvest } & S_brand & $(, 1663)$ &, 1590 & ,943 & $(, 636)$ & ,304 \\
\hline & S_geo_origin & ,0947 &, 1601 & ,997 & $(, 379)$ & ,568 \\
\hline & S_info_label & ,2979 &, 1594 &, 502 & $(, 173)$ & ,769 \\
\hline & S_awards & ,4037 &, 1598 &, 151 & $(, 069)$ & 876 \\
\hline & S_recommendation & $(, 3220)$ &, 1601 & ,409 & $(, 795)$ &, 151 \\
\hline & S_price &, 1132 &, 1601 & ,992 & $(, 360)$ & ,587 \\
\hline \multirow{6}{*}{ S_Geo_origin } & S_brand & $(, 2610)$ &, 1594 & ,658 & $(, 732)$ & ,210 \\
\hline & S_year_harvest & $(, 0947)$ &, 1601 & ,997 & $(, 568)$ & ,379 \\
\hline & S_info_label & ,2032 &, 1598 &, 865 & $(, 269)$ & ,676 \\
\hline & S_awards & ,3090 &, 1601 & ,461 & $(, 164)$ & ,782 \\
\hline & S_recommendation & $(, 4167)$ &, 1605 &, 129 & $(, 891)$ &, 058 \\
\hline & S_price &, 0185 &, 1605 & 1,000 & $(, 456)$ & ,493 \\
\hline \multirow{6}{*}{ S_Info_Label } & S_brand & $(, 4642)$ &, 1587 &, 055 & $(, 933)$ & 005 \\
\hline & S_year_harvest & $(, 2979)$ &, 1594 &, 502 & $(, 769)$ &, 173 \\
\hline & S_geo_origin & $(, 2032)$ &, 1598 &, 865 & $(, 676)$ & ,269 \\
\hline & S_awards &, 1058 &, 1594 & ,994 & $(, 365)$ & ,577 \\
\hline & S_recommendation & $(, 6199)^{*}$ &, 1598 &, 002 & $(1,092)$ & $(, 148)$ \\
\hline & S_price & $(, 1847)$ &, 1598 & ,910 & $(, 657)$ & ,288 \\
\hline
\end{tabular}




\begin{tabular}{|l|l|r|r|r|r|r|}
\hline \multicolumn{7}{|c|}{ Multiple Comparisons } \\
\hline \multirow{5}{*}{ S_Awards } & S_brand & $(, 5700)^{*}$ &, 1590 &, 007 & $(1,040)$ & $(, 100)$ \\
\cline { 2 - 7 } & S_year_harvest & $(, 4037)$ &, 1598 &, 151 & $(, 876)$ &, 069 \\
\cline { 2 - 7 } & S_geo_origin & $(, 3090)$ &, 1601 &, 461 & $(, 782)$ &, 164 \\
\cline { 2 - 7 } & S_info_label & $(, 1058)$ &, 1594 &, 994 & $(, 577)$ &, 365 \\
\cline { 2 - 7 } & S_recommendation & $(, 7256)^{*}$ &, 1601 &, 000 & $(1,199)$ & $(, 252)$ \\
\cline { 2 - 7 } & S_price & $(, 2904)$ &, 1601 &, 539 & $(, 764)$ &, 183 \\
\hline \multirow{5}{*}{ S_ } & S_brand &, 1557 &, 1594 &, 959 & $(, 316)$ &, 627 \\
\cline { 2 - 7 } & S_year_harvest &, 3220 &, 1601 &, 409 & $(, 151)$ &, 795 \\
\cline { 2 - 7 } & S_geo_origin &, 4167 &, 1605 &, 129 & $(, 058)$ &, 891 \\
\cline { 2 - 7 } & S_info_label &, $6199^{*}$ &, 1598 &, 002 &, 148 & 1,092 \\
\cline { 2 - 7 } & S_awards &, $7256^{*}$ &, 1601 &, 000 &, 252 & 1,199 \\
\cline { 2 - 7 } & S_price &, 4352 &, 1605 &, 097 & $(, 039)$ &, 910 \\
\hline \multirow{5}{*}{ S_Price } & S_brand & $(, 2795)$ &, 1594 &, 580 & $(, 751)$ &, 192 \\
\cline { 2 - 7 } & S_year_harvest & $(, 1132)$ &, 1601 &, 992 & $(, 587)$ &, 360 \\
\cline { 2 - 7 } & S_geo_origin & $(, 0185)$ &, 1605 & 1,000 & $(, 493)$ &, 456 \\
\cline { 2 - 7 } & S_info_label &, 1847 &, 1598 &, 910 & $(, 288)$ &, 657 \\
\cline { 2 - 7 } & S_awards &, 2904 &, 1601 &, 539 & $(, 183)$ &, 764 \\
\cline { 2 - 7 } & S_recommendation & $(, 4352)$ &, 1605 &, 097 & $(, 910)$ &, 039 \\
\hline *The mean differen & & & & \\
\hline \multirow{5}{*}{ Sence is significant at the 0.05 level.* } & & & \\
\hline
\end{tabular}

